\title{
The Impact of Oral Rehydration Therapy on Childhood Diarthoeal Disease in Ilorin
}

\author{
A. Ojuawo*, A NJoku**, O Adedoyin*
}

\section{Summary}

\begin{abstract}
Ojuawo A, Njoku A, Adedoyin O. The Impact of Oral Rehydration Therapy on Childhood Diarrhoeal Dieeave in Ilorin. Nigerian Journal of Paediatrics 2003,30:23.

Background: Diarthoeal disease remains a leading cause of morbidity and mortality in childhood. The advent of oral rehydration therapy (OR'T) including home treatment of diarthoen has affected the incidence of dehydration.

Objective: To assess the impact of oral rehydration therapy on childhood diarchoeal disease. Designi Cross sectional study.

Methoda: The duration of the diarrhoeal illness, the degree of dehydration, treatment given at home and the outcome were studied in children seen at the Diarrhoea Training Unit (DTU) of the University of Dorin Teaching Hospital during the periods July 1993 to June 1994 and July 1997 to June 1998.

Results: Eight hundred and ninety one patients presented in the DTU over the one-year period in 1993/94 compared to 109 patients over the same period in 1997/98. There was a significantly higher mean duration of diarrhoea before presentation in the 1993/94 group (58.3 \pm 13 hours) compared to the $1997 / 98$ group $(25.7 \pm 6.1$ hours $)(t=2.12, p<0.025)$. Severe dehydration was seen in 11 percent of the cases in the 1993/94 group compared to five percent in the 1997/98 group $\left(\chi^{2}=9.42, \mathrm{P}<0.01\right)$. Seventy-six percent of the patients in the $1993 / 94$ group and sixtysix percent in the 1997/98 group received various antidiarrhoeal drugs before presentation. Conclusion: The application of oral rehydration therapy resulted in the reduction of cases of severe dehydration seen in children with diarrhoea in llorin. The panents presented earliex in the 1997/98 than in the 1993/944 group but the use of antidiarchoeal drugs was still common. There is therefore, a need for further training of health workers and mothers on the home management of diarnoea. The use of drugs that axe not indicated in the management of diarnhoen should be discouraged, while ORT use showid be strengthened.
\end{abstract}

Key words: Diarthoea, Dehydration, Oral rehydration therapy, Anti-diarchoeal drugs.

\section{Introduction}

DIARRHOEAL disease remains a leading cause of morbidity and mortality in childhood in developing countries and dehydration is the major complication." ${ }^{3}$ Oral rehydration therapy is cheap, acceptable,

\section{University of Ilorin Teaching Hospital, Ilorin}

Department of Peediatrics

*Consultont Paediatrician

** Nurring Sister

Cormespondence: Dr Ayodele Ojuewo affordable, accessible and is an appropriate means of prevention and correction of dehydration, ${ }^{4 \cdot 7}$ which accounts for the majority of deaths in children with diarrhoeal disease. ${ }^{3-5}$ Until the advent of oral rehydration therapy (ORT), children were not receiving adequate rehydration at home, hence they ptesented in health facilities with severe dehydration, requiring intravenous fluid therapy. ${ }^{\circ}$ ORT was introduced in llorin in 1990, and series of training on the concept of ORT have been held at different levels of health care since then. The knowledge of ORT by both health care givers and parents seems to have changed the incidence and outcome of dehydration following 
diarrhoeal disease.? This study was aimed at assessing the impact of ORT on the incidence and outcome of dehydration in children with diarthoea.

\section{Patients and Methods}

The study was carried out in the Diarrhoea Training Unit (DTU) of the University of Ilorin Teaching Hospital in two stages for the purpose of comparison. The DTU is located in the Emergency Paediatric Unit (EPU), hence those requiring intravenous therapy are managed in the emergency ward. The unit is open for
24 hours a day, and coverage is by the staff in the EPU. There were other health facilities at which the patients could have sought medical care, but such facilities were the same over the period of the two stages of the study. The provision of water and sanitation facilities were also comparable over the study period. The first stage was from July 1993 to June 1994 , while the second was between July 1997 and June 1998. Children presenting with diarrhoeal disease at the DTU during the study period were recruited into the study. Diarthea in this study refers to an increase in the fluidity of stool (a stool is fluid when it takes the shape of the container).

Table I

Comparative Features in Children presenting with Diarrboea

\begin{tabular}{llll}
\hline Feature & $1993 / 94$ & $1997 / 98$ & $p$ \\
\hline Number & 891 & 109 & \\
Male: Female & $1.3: 1$ & $1.4: 1$ & $\mathrm{NS}$ \\
Average number of stools/day & 4 & 3.8 & $\mathrm{NS}$ \\
Average age at presentation (yrs) & $1.7 \pm 0.42$ & $2.1 \pm 0.38$ & $\mathrm{NS}$ \\
Age $<2$ years & $87 \%$ & $83 \%$ & $\mathrm{NS}$ \\
Mean weight (kg) & $9.2 \pm 2.1$ & $9.7 \pm 2.5$ & $\mathrm{NS}$ \\
Mean duration of diarthoea & & & \\
$\quad$ before presentation (hrs) & $58.3 \pm 13$ & $25.7 \pm 6.1$ & $<0.025$ \\
Type of dehydration & & & \\
mild & $545(61.2 \%)$ & $78(62.4 \%)$ & $\mathrm{NS}$ \\
$\quad$ moderate & $248(27.8 \%)$ & $25(22.9 \%)$ & $\mathrm{NS}$ \\
$\quad$ severe & $98(11 \%)$ & $6(5.5 \%)$ & $<0.025$ \\
\hline
\end{tabular}

*NS $=$ not significant

Table II

Treatments given at Hame before Presentation in the Tuo Groups

\begin{tabular}{lccl}
\hline Treasment & $\begin{array}{c}1993 / 94 \\
\text { No. } \%)\end{array}$ & $\begin{array}{c}1997 / 98 \\
\text { No. } \%)\end{array}$ & $p$ \\
\hline $\begin{array}{l}\text { Oral rehydration therapy } \\
\text { Total }\end{array}$ & $59(6.6)$ & & \\
SSS & $20(33.9)$ & $24(22.1)$ & $<0.01$ \\
ORS & $39(66.1)$ & $8(33.3)$ & NS* \\
Drugs & & $16(66.6$ & NS \\
Metronidazole & $338(37.9)$ & $41(37.6)$ & NS \\
Cotrimoxazole & $288(32.3)$ & $37(33.9)$ & NS \\
Diastop(Q & $283(31.7$ & $35(32.1)$ & NS \\
Thalazole & $53(5.9)$ & $3(2.7)$ & $<0.05$ \\
Mist Kaolin & $45(5.1)$ & $3(2.7)$ & $<0.05$ \\
Traditional drugs & $85(9.5$ & $1(0.9)$ & $<0.02$ \\
Others & $35(3.9)$ & $3(2.7)$ & NS \\
\hline
\end{tabular}

*NS = not significant 
Patients who had severe malnutrition and other systemic diseases were excluded from the study. The age, sex, duration of diarhoea before presentation, remedies given at home, anthropometric measurements, degree of dehydration, treatment given in the DTU, duration of hospitalization and outcome of the disease were recorded for both groups. Those that were assessed to have some dehydration were managed with oral rehydration therapy along the National Control of Diarrhoea Disease (CDD) guidelines, while those with severe dehydration received intravenous fluids.

\section{Statistical analysis}

Data generated were analyzed by determining the distribution of variables and Chi square was used to test the degree of association, and the mean of the two groups were compared using Student's ' $t$ '-test with a $\mathrm{p}$ value $<0.05$ being significant.

\section{Results}

Eight hundred and ninety one patients presented in the DTU over the period of one year in 1993/94 compared to 109 patients over a similar period in $1997 /$ 98. The male to female ratio was comparable in both groups with a male preponderance (1.3: 1 in 1993/94 versus 1.4: 1 in 1997/98). The mean duration of diarrhoea before presentation was significantly higher in the $1993 / 94$ group ( $58.3 \pm 13$ hours) compared to the 1997/98 group ( $25.7 \pm 6.1$ hours) $(\mathrm{p}<0.025$; Table 1). In both groups, over 80 percent of the cases were below the age of two years. Ninety-eight (11 percent) of the cases in the 1993/94 group were severely dehydrated, compared to six cases ( 5.5 percent) in the $1997 / 98$ group $\left(\chi^{2}=9.42, \mathrm{p}<0.01\right)$.

Table II shows that only 59 ( 6.6 percent) of the mothers gave ORT either as commercially prepared ural rehydration salt (ORS) or salt suigar solution (SSS) in the 1993/94 group whereas $24(22.1$ percent) did in the $1997 / 98$ group $(p<0.01)$. Fifty-five of the 83 mothers ( 66.3 percent) who gave ORT at home before presentation at the health facility used the commercially prepared ORS rather than SSS in both groups. In the 1993/94group, 621(76.7 percent) had received various drugs singly or in combination whilst 72 (66.1 percent) patients received drugs before presentation in the 1997/98 group.Such drugs included metronidazole in 338 ( 38 percent), cotrimoxazole in 288 ( 32 percent), and Diastop in $283(32$ percent). The rate of use of these drugs was comparable in both groups.

\section{Discussion}

The reduction in the incidence of severe dehydration in chiltren with diarrhoeal disease observed in this study probably reflects an increased awareness of the benefit of oral rehydration therapy by the mothers who commenced the treatment at home early enough, thus preventing dehydration and reducing the incidence of severe dehydration. ORT has been proven to be efficacious in preventing dehydration if started early. ${ }^{45,9,10}$ The use of oral rehydration therapy at home before presentation at the health facility had improved from six pencent in 1993/94 to twenty two percent in $1997 / 98$, a finding that is similar to what had been reported by other workers. ${ }^{11}$ Home treatment is an essential part of the correct management of diarthoea. The correct use of ORT will save most lives, with fewer cases dying because of prompt action taken at home.

Although there were other health facilities besides ours where the patients could have sought health care, such facilities were equally available to both study groups, hence this potential variable is unlikely to have accounted for the observed results in this study. It is however, conceded that the training of the staff in the interval between the periods of the study could possibly have affected the management of the cases before presentation, hence the reduced incidence of severe dehydration.

A majority of the mothers used ORS at home instead of SSS, a practice that is at variance with the Nigerian policy on control of diarrhoeal disease. ${ }^{12}$ SSS is recommended for home use while ORS is expected to be used under supervision at the health facility. The mothers used the commencially prepared ORS pmbably because of the convenience of preparation and its presumed medicinal value. The use of antidiarrhoeal drugs remains a problem. Most of the children received one form of antidiarthoeal remedy or the other before presentation, a finding that is similar to previous findings. ${ }^{13,14}$ This trend continues despite the public enlightenment campaign being mounted to discourage the use of these remedies, which have been proven to be useless, and could in fact, be dangerous. ${ }^{15,16}$ There is therefore, a need to reinforce the information concerning the use of antidiarrioeal drugs and the benefit of SSS in the home management of diarthoeal diseases in childhood. There is also a need for further training and retraining of health workers and the mothers on the home management of diarthoea.

It is gratifying to observe that the use of oral rehydration therapy at home at the onset of diarrhoea has increased in Ilorin. Coupled with this is the early presentation of the patients at the health facility, which was reflected in the reduction of the cases of severe dehydration seen in the DTU in Ilorin. 


\section{References}

1. Ransome-Kuti $O$. The problem of paediatric emergencies in Nigeria. Nig Med J 1972; 2; 62-70.

2. Kaine W, Okolie I. A xeview of the causes of hospitalisation as a guide to the pattern of disease in Eastern Nigeria. Nig Med J 1975; 7: 205-9.

3. Isaacs D, Day D, Crooks D. Childhood gastroenteritis: a population study. Br Med J 1986; 293: 545-6.

4. Ransome-Kuti $O$, Bamisaiye $A$. Oral therapy of infant dianchoea (letter). Lancer 1978; $2 ; 7$.

5. A manual for the treatment of diarthea for ure by physicians and other senior health workers. WHO/CDD/SER/ $80.2 \operatorname{Rev} 2,1990$.

6. Patra FC, Mahalanabis D, Jalan KN, Sen A, Banerjee P. Is oral rice electrolyte solution superior to glucose dectrolyte solusion in infant diarrhoea? Anth Dis Child 1982; 57: 910-2.

7. Ebrahion GJ. Oral rehydration thexapy in the 19908. J Trop Pediatr 1989; 35: 209-10.

8. Murga $H$, Huicho $L$, Guevara G. Acute diarthoea and campylobacter in Peruvian children: a clinical and epidemiologic approach. I Trop Pediatr 1993; 39: 338 41 .

9. Prasad B. Rice based oral rehydration solution: a controlled trial in Nepal. J Trop Pediatr 1993; 39; 368-9.

10. Loxes $\mathrm{H}$, Burbano J. Cholera situation in the Americas. Epidemiol Bull 1991; 12:1.

11. Readings on diarchoea (Student's manual). Adapted manual of WHO for the control of diaxthoea diseases. 1990:48.

12. Pormoy BL, Dupont HL, Pritt D. Antidianthoeal agents in the treatment of acute diarchea in children. JAMA 1976; 236: 8446.

13. Ojuawo $A$, Adedoyin OT. Treatmest of diarmoea by proprietary medicine vendore in Moxin. Nig J Paeckiatr 1993; 20: 41-4.

14. Goodburn E, Mattoraho S, Mangi P, Waterston T. Management of childhood diarchoea by pharnacists and parents: is Britain lagging behind the third wodd? BMJ 1991; 302: 440-3.

15. Walia BNS, Agrawal SM, Agrawal KC, Panhotra BR, Manchada KS. Drugs in the treatment of dianhoea. Ind J Paeciastr 1980, 47: 323-7. 